\title{
Optimal Income Taxation and Social Norms in the Labor Market*
}

\author{
Thomas Aronsson and Tomas Sjögren \\ Department of Economics, Umeå University, \\ SE - 90187 Umeå, Sweden
}

February 2006

\begin{abstract}
This paper concerns optimal income taxation in a two-type model extended to allow for social interaction and social norms in the labor market. One type of norm relates to the hours of work among the employed, and we assume that there is a cost associated with deviating from 'normal behavior' (defined in terms of the average hours of work). Another type of norm refers to the pressure of earning one's living by working, where social interaction means that the perceived cost of being out of employment depends on the share of nonworkers in the population. The results show how, and why, the existence of social norms may modify results derived in earlier literature. Under reasonable assumptions, the norm referring to normal behavior in term of work hours provides an incentive for the government to increase the hours of work supplied by the high-ability type relative to the hours of work supplied by the low-ability type, whereas the norm of 'earning one's living by working' strengthens the employment-motive behind tax policy.

JEL Classification: D60, H21, H53

Keywords: Optimal Taxation, Social Interaction, Norms
\end{abstract}

*The authors would like to acknowledge a research grant from FAS. 


\section{Introduction}

There is a large literature dealing with different aspects of social norms; in particular, how such norms affect the behavior of individuals and/or the resulting consequences for macroeconomic outcomes. A basic message of earlier research is that, although individual behavior might be constrained by social norms, these norms may, in fact, magnify the behavioral and welfare effects of public policy, as norms may errode over a longer time perspective ${ }^{1}$. As such, the potential existence of social norms is very important for our understanding of the welfare consequences of public policy. Despite this, the literature on optimal general income taxation has not (to our knowledge) considered the possibility that social norms may influence the resource allocation $^{2}$. The purpose of this paper is to incorporate social norms related to the labor market into the framework for studying optimal income taxation developed by Stern (1982) and Stiglitz (1982).

Why are social norms, and their consequences for labor market outcomes, interesting to consider in the context of optimal income taxation? First, income from employment constitutes the most important source of income for a majority of individuals in any industrialized country. This suggests that, if social norms affect the labor market outcome, then the consequences of these norms are potentially relevant from the perspective of labor income

\footnotetext{
${ }^{1}$ See e.g. Lindbeck (1995). See also Jakee and Sun (2005), who analyze a dynamic economy with external habit formation (formalized by assuming that the average consumption of leisure in the economy as a whole affects the utility of each individual). The results imply that income redistribution policies may lead to a continuous increase in the share of the population living on publicly provided benefits and a continuous decrease in the hours of work over time.

${ }^{2}$ Wendner (2005) analyzes efficient taxation of labor income and emissions in a framework with status seeking and habit formation. However, his model differs substantially from ours in terms of focus, norm formation and tax instruments.
} 
taxation. Second, and equally important, the labor market is often thought of as being one of the main dimensions for behavioral responses to income redistribution; the latter being an important purpose behind the labor income tax. Therefore, if social norms modify the results derived in previous studies, this adds to our understanding of how income taxation might be used to reach an efficient outcome while at the same time serving as one of the main instruments for income redistribution.

Although in a different context than our study, earlier literature dealing with social norms and employment emphasizes, at least, two different types of norms. One type of norm refers to 'normal behavior' with regards to work hours ${ }^{3}$ and might be relevant primarily for those individuals who are in employment. The basic idea is that individuals may compare themselves with a reference group, and that there is a cost associated with deviating from the normal behavior (often defined as the average hours of work) in this group ${ }^{4}$. Another type of norm reflects the pressure to earn one's income from work; alternatively the pressure against living on transfers from the public sector. In other words, there may be a (perceived) cost of being out of employment which, in part, determines whether an individual actively seeks employment, or whether he/she attempts to live on publicly provided benefits. Social interaction may here imply that the cost of being out of employment, for any individual, depends on the behavior of others. One idea explored in earlier research is that the lower (higher) the fraction of

\footnotetext{
${ }^{3}$ This is one of the ideas emphasized in the literature dealing with the labor supply under interdependent behavior. For more thorough discussions of labor supply and interdependent behavior, see e.g. Blomquist (1993), Woittiez and Kapteyn (1998) and Aronsson et al. (1999).

${ }^{4}$ This also relates to the idea that the self-image depends on how the actual behavior deviates from the behavior required by the norm. See e.g. Bruvoll and Nyborg (2004); in their study, self-image is part of a model used to analyze recycling behavior.
} 
nonworking transfer recipients in the population, the higher (lower) this cost to the individual ${ }^{5}$. Both types of norms - relating to the hours of work among the employed and the pressure to earn one's living by working, respectively - will be addressed below.

The paper contributes to the literature in at least two ways. First, we incorporate social interaction along the lines discussed above into a model, which is designed for analyzing optimal general income taxation. This enables us to connect the study of optimal taxation to earlier literature dealing with the behavioral and welfare effects of social norms. In addition, since we are considering a general income tax, the analysis also enables us to address the interesting question of whether the existence of social norms in the labor market provides an argument for tax distortions at the second best optimum. Second, by allowing for employment-related motives behind tax policy, our study relates to other literature on optimal income taxation under imperfect competition in the labor market $^{6}$, where earlier research concentrates on the consequences of involuntary unemployment (due to union wage formation). Therefore, by focusing on other aspects of the labor market than this earlier literature, the paper also provides a broader understanding of how the functioning of the labor market contributes to the optimal income tax structure.

In accordance with much of the earlier literature on optimal income taxation, we distinguish between two employed ability-types; a high-ability type and a low-ability type, respectively, whereas those who do not work receive a transfer payment from the public sector. As such, this transfer may reflect social insurance or social assistance; however, as we do not attempt to include health and/or life-cycle aspects in the model, we cannot make a formal distinction between different types of transfers. The government is

\footnotetext{
${ }^{5}$ See e.g. Lindbeck et al. (1999, 2003).

${ }^{6}$ See e.g. Fuest and Huber (1997) and Aronsson and Sjögren (2004).
} 
subject to the (conventional) informational restriction that, while it can observe the income of any individual, ability is private information. In Section 2, we present the model and the outcome of private optimization. Section 3 contains a description of the government's decision problem and the results in terms of optimal income taxation. Finally, the results are summarized and discussed in Section 4.

\section{The Model}

As indicated above, we make a distinction between two types of employed consumers; a low-ability type (denoted by superindex 1) and a high-ability type (denoted by superindex 2). This distinction refers to productivity, which is here interpreted to mean that the high-ability type faces a higher before tax wage rate than the low-ability type. We denote by $N^{1}$ and $N^{2}$, respectively, the number of individuals of each such ability-type.

The utility function facing an employed individual of ability-type $i$ is given by

$$
U^{i}=u\left(c^{i}, z^{i}\right)-\frac{1}{2} \rho\left[\bar{l}-l^{i}\right]^{2}
$$

where $c^{i}$ denotes consumption and $z^{i}$ leisure. Leisure is, in turn, defined as a time endowment, $H$, less the time spent in market work, $l^{i}$. The function $u(\cdot)$ is assumed to be increasing in $c^{i}$ and $z^{i}$ as well as strictly quasiconcave. The second part of equation (1) is a loss function, which is assumed to be quadratic for notational convenience, where $\rho>0$ is a fixed parameter. We assume that the average hours of work among the employed, $\bar{l}$, constitutes the social norm for work hours, so the second part of the utility function measures the utility loss of deviating from the average hours of work ${ }^{7}$. Each

\footnotetext{
${ }^{7}$ One possible, and likely, effect of a social norm with respect to the hours of work is
} 
individual treats $\bar{l}$ as exogenous during optimization. The budget constraint is written

$$
w^{i} l^{i}-T\left(w^{i} l^{i}\right)-c^{i}=0
$$

where $T(\cdot)$ a general income tax. The first order condition for the hours of work becomes

$$
\frac{\partial u^{i}}{\partial c^{i}} w\left[1-T^{\prime}\left(w^{i} l^{i}\right)\right]-\frac{\partial u^{i}}{\partial z^{i}}+\rho\left[\bar{l}-l^{i}\right]=0
$$

where $u^{i}=u\left(c^{i}, z^{i}\right)$, while $T^{\prime}(\cdot)=\partial T(\cdot) / \partial\left(w^{i} l^{i}\right)$ is the marginal income tax rate. If $l^{2}>l^{1}$ (which appears to be a reasonable assumption), it follows that the low-ability type tends to choose more hours of work and the highability type less hours of work than in the absence of the social norm. For the analyses to be carried out later, note also that $\partial l^{i} / \partial \bar{l}>0$, meaning that an increase in the average hours of work contributes to increase the hours of work chosen by individuals of both ability-types.

Individuals who do not work, to be called 'nonworkers' in what follows, receive a benefit, $b$, from the public sector. The budget constraint becomes $b-c^{0}=0$, where the superindex " 0 " is used to denote 'nonworker'. There are $N^{0}$ 'genuine' nonworkers, who are unable to work (for whatever reason), and whom the government wants to support. The utility of each such genuine nonworker is given by $U^{0}=\tilde{u}\left(c^{0}, H\right)$, where the symbol " $\sim$ " is used to indicate that the genuine nonworkers may have different preferences (for instance, a higher marginal utility of leisure) than the workers. Other possible that individuals with low productivity may work too much, whereas the opposite applies for individuals with high productivity. Our approach provides a simple framework for capturing these possible effects. Another approach would be to make the norm typespecific. However, this complicates the analysis, as it may require that individuals of the same ability-type differ with respect to work hours; for instance, due to differences in the utility loss of deviating from the (type-specific) average hours of work. 
nonworkers, i.e. agents who prefer to become nonworkers instead of being employed, will be discussed below.

The production technology is linear, which means that the wage rate is fixed. This assumption simplifies the analysis; it is not important for the qualitative results to be derived with respect to the consequences of social interaction for optimal taxation.

As mentioned above, we would like to capture the idea that some individuals of each ability-type, who are able to work, may choose to become nonworkers; at least if the benefits paid out to nonworkers by the government are sufficiently large. Furthermore, we assume that the government is unable to discriminate between genuine and other nonworkers. Therefore, even if the number of genuine nonworkers is common knowledge, the government does not know whether any given nonworkers is unable to work or has chosen to become a nonworker. In our framework, the choice of whether to work or become a nonworker depends on the norm that one should live on one's own work (provided that one is able to do so), implying that there is a perceived cost to the individual of being a nonworker. We make two additional assumptions; (i) the cost of being a nonworker varies between individuals, and (ii) the cost facing any given individual decreases with the share of nonworkers in the population. By ranking the $N^{i}$ individuals of ability-type $i$ with respect to the perceived cost, from lowest to highest, of being a nonworker, the number of nonworkers of ability-type $i, n^{i}$, is implicitly defined by the equation

$$
u\left(c^{i}, z^{i}\right)-\frac{1}{2} \rho\left[\bar{l}-l^{i}\right]^{2}-\left\{u\left(c^{0}, H\right)-\psi_{n}^{i}\left(\check{N}, n^{i}\right)\right\}=0
$$

for $i=1,2$, where the expression within square brackets (the third and fourth terms on the left hand side) measures the utility of the $n^{i}$ :th individual of ability-type $i$ if he/she chooses to become a nonworker. The term $\psi_{n}^{i}(\cdot)$ 
is the perceived cost of being a nonworker facing the $n^{i}$ :th individual of ability-type $i$ in terms of the ranking referred to above, $\check{N}=\left[N^{0}+n^{1}+\right.$ $\left.n^{2}\right] / M$ the fraction of nonworkers in the population and $M=N^{0}+N^{1}+$ $N^{2}$ the total population. The function $\psi_{n}^{i}(\cdot)$ is such that $\partial \psi_{n}^{i}(\cdot) / \partial \check{N}<0$ and $\partial \psi_{n}^{i}(\cdot) / \partial n^{i}>0$. To ensure that a higher cost of being a nonworker, ceteris paribus, also means a smaller utility gain (or a greater utility loss) of switching from the working to the nonworking state, we also assume that the left hand side of (4) increases monotonically with $n^{i}$.

Let $\check{N}^{1}=N^{1}-n^{1}$ and $\check{N}^{2}=N^{2}-n^{2}$ be the number of working lowability and high-ability types, respectively, and $\check{N}^{0}=N^{0}+n^{1}+n^{2}$ the total number of nonworkers. By solving equations (4), while recognizing that $\bar{l}=\bar{l}\left(l^{1}, l^{2}, n^{1}, n^{2}\right)=\left[\check{N}^{1} l^{1}+\check{N}^{2} l^{2}\right] /\left[\check{N}^{1}+\check{N}^{2}\right]$, we have

$$
\begin{aligned}
& n^{1}=n^{1}\left(c^{1}, l^{1}, c^{2}, l^{2}, c^{0}\right) \\
& n^{2}=n^{2}\left(c^{1}, l^{1}, c^{2}, l^{2}, c^{0}\right)
\end{aligned}
$$

in which the constants $N^{1}$ and $N^{2}$ have been suppressed for notational convenience. Note that the incentive to become a nonworker for any ability-type depends on the variables characterizing the other ability-type as well. The latter is, in part, a consequence of the assumption that, for each ability-type, the cost of being a nonworker depends on the fraction on nonworkers in the population.

Each consumer is assumed to correctly anticipate (and treat as exogenous), the values of the policy instruments chosen by the government as well as the 'aggregate variables' $\bar{l}, n^{1}$ and $n^{2}$. A Nash equilibrium in the private sector means that the private budget constraints as well as equations (3), (5) and (6) are fulfilled simultaneously. In what follows, we assume that the private sector has reached such a Nash equilibrium, and that it is characterized by $n^{1} \in\left(0, N^{1}\right)$ and $n^{2} \in\left(0, N^{2}\right)$. 


\section{The Optimal Tax and Expenditure Problem}

We begin by discussing the objective and constraints facing the government. With this decision problem at our disposal, we continue by analyzing the outcome in terms of optimal taxation.

\subsection{The Decision Problem of the Government}

We concentrate on Pareto efficient taxation, which will be analyzed by maximizing the utility of one of the agent-types subject to minimum utility restrictions for the others. Suppose that the government behaves as if it maximizes the utility of the employed low-ability type subject to minimum utility restrictions for the employed high-ability type and the genuine nonworkers, respectively. These minimum utility restrictions can be written as

$$
\begin{gathered}
u\left(c^{2}, z^{2}\right)-\frac{1}{2} \rho\left[\bar{l}-l^{2}\right]^{2}-\bar{U}^{2} \geq 0 \\
\tilde{u}\left(c^{0}, H\right)-\bar{U}^{0} \geq 0
\end{gathered}
$$

where $\bar{U}^{2}$ and $\bar{U}^{0}$ are fixed.

The informational assumptions are conventional: the government knows the income of each individual as well as the number of individuals of each agent-type, whereas ability is private information. The latter means that, in the absence of appropriate type-revealing mechanisms, the government would not be able to observe whether any given worker is a low-ability or high-ability type. By concentrating on the 'normal' case, where redistribution means income transfers from high income earners to low income earners, one would like to prevent the high-ability type from pretending to be a lowability type. The corresponding self-selection constraint becomes 


$$
U^{2}=u\left(c^{2}, z^{2}\right)-\frac{1}{2} \rho\left[\bar{l}-l^{2}\right]^{2} \geq u\left(c^{1}, H-\phi l^{1}\right)-\frac{1}{2} \rho\left[\bar{l}-\phi l^{1}\right]^{2}=\hat{U}^{2}
$$

where $\hat{U}^{2}$ denotes the utility of a high-ability mimicker, and $\phi=w^{1} / w^{2}<1$ is the relative wage rate.

The budget coinstraint facing the government can be written as

$$
\check{N}^{1} w^{1} l^{1}+\check{N}^{2} w^{2} l^{2}-\check{N}^{1} c^{1}-\check{N}^{2} c^{2}-\check{N}^{0} c^{0}
$$

in which we have used the private budget constraints, $T^{1}\left(w^{1} l^{1}\right)=w^{1} l^{1}-c^{1}$, $T^{2}\left(w^{2} l^{2}\right)=w^{2} l^{2}-c^{2}$ and $c^{0}=b$, respectively.

With a general income tax, the government can effectively choose any desired combination of work hours and consumption for each ability-type, meaning that it is more convenient to use $l^{1}, c^{1}, l^{2}$ and $c^{2}$, instead of the parameters of the income tax function, as the direct decision variables. Therefore, the optimization problem facing the government is to choose $l^{1}, c^{1}, l^{2}$, $c^{2}$ and $c^{0}$ such as to maximize the utility of the low-ability type subject to the minimum utility restrictions, the self-selection constraint and the budget constraint, as well as subject to equations (5) and (6) which define the number of individuals of each ability-type who choose to become nonworkers as a function of the policy instruments. The Lagrangean is written

$$
\begin{aligned}
L= & U^{1}+\delta U^{2}+\zeta U^{0}+\lambda\left[U^{2}-\hat{U}^{2}\right] \\
& +\gamma\left[\check{N}{ }^{1} w^{1} l^{1}+\check{N}^{2} w^{2} l^{2}-\check{N}^{1} c^{1}-\check{N}^{2} c^{2}-\check{N}^{0} c^{0}\right]
\end{aligned}
$$

where $\delta, \zeta, \lambda$ and $\gamma$ are Lagrange multipliers, whereas $U^{1}, U^{2}, U^{0}, \hat{U}^{2}, \check{N}^{1}$, $\check{N}^{2}$ and $\check{N}^{0}$ were defined above. The first order conditions are presented in the Appendix. 


\subsection{Optimal Taxation}

Given the framework set out above, our purpose is to analyze the optimal tax structure. In particular, our concern will be to examine whether the appearance of social norms in the context of the labor market constitutes a motive for using distortionary labor income taxation.

Special Case: Social Interaction with Respect to the Hours of Work

It is convenient to begin by briefly considering the special case, where (i) the ability of each employed individual is fully observed, and (ii) the norm that one should live on one's own work is strong enough to imply that all individuals (who are able to work) prefer employment over nonparticipation at the second best optimum. In terms of the model set out above, these simplifications imply that $\lambda=n^{1}=n^{2}=0$. This special case enables us to concentrate on the implications of the social norm with respect to the hours of work, which is clearly relevant from the perspective of earlier research on labor supply. It will also simplify the presentation of results in later parts of the paper. Consider Proposition 1;

Proposition 1 If $\lambda=n^{1}=n^{2}=0$ at the optimum, the marginal income tax rates can be written as

$$
\begin{aligned}
T^{\prime}\left(w^{1} l^{1}\right) & =\frac{\rho\left[\bar{l}-l^{1}\right]+\delta \rho\left[\bar{l}-l^{2}\right]}{w^{1}\left(\partial U^{1} / \partial c^{1}\right)} \frac{\partial \bar{l}}{\partial l^{1}} \\
T^{\prime}\left(w^{2} l^{2}\right) & =\frac{\rho\left[\bar{l}-l^{2}\right]+\rho\left[\bar{l}-l^{1}\right] / \delta}{w^{2}\left(\partial U^{2} / \partial c^{2}\right)} \frac{\partial \bar{l}}{\partial l^{2}}
\end{aligned}
$$

Proof: See the Appendix.

The intuition behind Proposition 1 is straight forward. If ability were fully observable, and if the perceived cost of being a nonworker were sufficiently high for all agents, then the government would be able to redistribute by means of ability-type specific lump-sum taxes together with the transfer 
payment to the genuine nonworkers (without creating strong enough incentives for nonparticipation among those who are able to work). As a consequence, the only remaining reason for using distortionary income taxation is that agents adapt to a social norm by modifying their hours of work. In other words, we would like to internalize the external effect following as the average hours of work is an argument in the utility functions (and treated as exogenous in the context of private optimization).

To be able to interpret Proposition 1, suppose that the hours of work increase with productivity, so $l^{2}>l^{1}$. In this case, starting with the tax formula for the low-ability type, the first term on the right hand side, $\rho\left[\bar{l}-l^{1}\right]\left[\partial \bar{l} / \partial l^{1}\right]$, is positive. This effect serves to decrease $l^{1}$ and, therefore, $\bar{l}$ which, in turn, contributes to reduce the utility loss for the low-ability type due to the social norm. As such, it prevents the low-ability type from adapting to the norm by choosing too many work hours from the perspective of society. Therefore, without a minimum utility restriction on the high-ability type, this would imply a positive marginal income tax rate for the low-ability type. However, this effect is, at least in part, offset by the second term on the right hand side, $\delta \rho\left[\bar{l}-l^{2}\right]\left[\partial \bar{l} / \partial l^{1}\right]$, which is negative and contributes to decrease the marginal income tax rate. The intuition is that a higher $l^{1}$ increases $\bar{l}$ which, in turn, reduces the utility loss for the high-ability type due the social norm. This serves to prevent the high-ability type from adapting to the norm by choosing too few hours of work from the perspective of society.

We can interpret the tax formula for the high-ability type in a similar way. The first term on the right hand side, $\rho\left[\bar{l}-l^{2}\right]\left[\partial \bar{l} / \partial l^{2}\right]$, is negative and serves to offset the tendency for the high-ability type to adapt to the norm by choosing too few hours of work. On the other hand, the the second term, $\rho\left[\bar{l}-l^{1}\right]\left[\partial \bar{l} / \partial l^{2}\right] / \delta$, is positive and contributes to reduce the hours of work by 
the high-ability type which, in turn, reduces $\bar{l}$ and, therefore, also the hours of work by the low-ability type. The latter is desirable, as we mentioned above, since the low-ability type tends to adapt to the norm by choosing too many hours of work.

The following result is an immediate consequence of Proposition 1;

Corollary 1: Suppose that $\lambda=n^{1}=n^{2}=0$ at the optimum, and that the hours of work increase with productivity, so $l^{2}>l^{1}$. Then, in the special case with a utilitarian social welfare function, where $\delta=1$, and if $N^{2}>$ $(<) N^{1}$, the two marginal income tax rates are positive (negative).

Although the exact result in Corollary 1 is due to the functional form of the loss function, the qualitative message is, nevertheless, more general; the distribution of ability-types determines (to some extent) whether a social norm with respect to the hours of work constitutes a motive for taxing or subsidizing labor at the margin ${ }^{8}$.

\section{The General Model}

Let us now turn to the more general model described in section 2 . Since the average hours of work is treated as exogenous in the context of the individual hours of work decision, it is useful to make a distinction between the private and social marginal rates of substitution between leisure and consumption for each ability-type. The the private marginal rate of substitution between leisure and consumption is defined in the usual way, given the functional form assumptions made above. For an individual of ability-type $i$, we have

$$
M R S_{z, c}^{i}=\frac{\partial u\left(c^{i}, z^{i}\right) / \partial z^{i}-\rho\left[\bar{l}-l^{i}\right]}{\partial u\left(c^{i}, z^{i}\right) / \partial c^{i}}
$$

\footnotetext{
${ }^{8}$ If $N^{1}$ is large relative to $N^{2}$, then the high-ability type faces a greater utility loss due to the social norm than the low-ability type, suggesting that the argument for subsidizing labor at the margin may dominate. If, on the other hand, $N^{2}$ is large relative to $N^{1}$, the opposite argument applies.
} 
where the numerator is interpretable as the private marginal utility of leisure (the negative of the private marginal utility of labor), which is defined conditional on $\bar{l}$. In a similar way, the ability-type specific social marginal rate of substitution is given by

$$
M R S S_{z, c}^{i}=M R S_{c, z}^{i}+\frac{\rho\left[\bar{l}-l^{i}\right]\left[\partial \bar{l} / \partial l^{i}\right]}{\partial u\left(c^{i}, z^{i}\right) / \partial c^{i}}=-\frac{\partial U^{i}}{\partial l^{i}}
$$

in which case we also recognize how $l^{i}$ affects $\bar{l}$ in terms of the utility function of ability-type $i$. The corresponding expression for the mimicker becomes

$$
\widehat{M R S S}_{z, c}^{2}=\frac{\left[\partial u\left(c^{1}, \hat{z}^{2}\right) / \partial \hat{z}^{2}\right] \phi-\rho\left[\bar{l}-\phi l^{1}\right]\left[\phi-\partial \bar{l} / \partial l^{1}\right]}{\partial u\left(c^{1}, \hat{z}^{2}\right) / \partial c^{1}}
$$

where $\hat{z}^{2}=H-\phi l^{1}$. In addition, define $\Delta^{i}$ as a short notation for the derivative of the Lagrangean with respect to $n^{i}$, i.e. $\Delta^{i}=\partial L / \partial n^{i}$. The marginal income tax rates are defined in Proposition 2 below;

Proposition 2 Within the given framework, the marginal income tax rates are characterized by

$$
\begin{aligned}
T^{\prime}\left(w^{1} l^{1}\right)= & \frac{1}{w^{1} \check{N}^{1}}\left[\frac{\left\{\left[\bar{l}-l^{1}\right]+\alpha^{1} \rho\left[\bar{l}-l^{2}\right]\right\}}{\partial U^{1} / \partial c^{1}} \frac{\partial \bar{l}}{\partial l^{1}} \check{N}^{1}\right. \\
& +\lambda^{*}\left\{M R S S_{z, c}^{1}-\widehat{\left.M R S S_{z, c}^{i}\right\}}\right. \\
& \left.-\sum_{i} \frac{\Delta^{i}}{\gamma}\left\{\frac{\partial n^{i}}{\partial l^{1}}+M R S S_{z, c}^{i} \frac{\partial n^{i}}{\partial c^{1}}\right\}\right] \\
T^{\prime}\left(w^{2} l^{2}\right)= & \frac{1}{w^{2} \check{N}^{2}}\left[\frac{\left\{\rho\left[\bar{l}-l^{2}\right]+\alpha^{2} \rho\left[\bar{l}-l^{1}\right]-\alpha^{2} \lambda \rho\left[\bar{l}-\phi l^{1}\right]\right\}}{\partial U^{2} / \partial c^{2}} \frac{\partial \bar{l}}{\partial l^{2}} \check{N}^{2}\right. \\
& \left.-\sum_{i} \frac{\Delta^{i}}{\gamma}\left\{\frac{\partial n^{i}}{\partial l^{2}}+M R S S_{z, c}^{i} \frac{\partial n^{i}}{\partial c^{2}}\right\}\right]
\end{aligned}
$$

where $\alpha^{1}=\left(\partial U^{1} / \partial c^{1}\right)(\delta+\lambda) /\left(\gamma \check{N}^{1}\right), \alpha^{2}=\left(\partial U^{2} / \partial c^{2}\right) /\left(\gamma \check{N}^{2}\right)$ and $\lambda^{*}=$ $\lambda\left(\partial \hat{U}^{2} / \partial c^{1}\right) / \gamma$. 
The proof of Proposition 2 is analogous to the proof of Proposition 1 and is, therefore, omitted. Let us start with the tax formula for the low-ability type. The first row on the right hand side is analogous to, and has the same interpretation as, the tax formula presented in Proposition 1. As such, it captures the corrective motive for taxation discussed above, which follows because a social norm affects the hours of work decision.

The second row reflects the self-selection constraint. The main difference in comparison with earlier research on redistribution with general income taxation is that this effect is here defined in terms of the ability-type specific social (instead of private) marginal rates of substitution; there is a discrepancy between these two concepts, since each individual treats $\bar{l}$ as exogenous. The general interpretation is, nevertheless, analogous to the interpretations given to the self-selection effect in earlier research. Therefore, if $M R S S_{z, c}^{1}>$ $(<) \widehat{M R S S}_{z, c}^{2}$, then the government may relax the self-selection constraint by choosing a higher (lower) marginal income tax rate for the low-ability type than it would otherwise have done.

The third row is interpretable as employment effects, and reflects an incentive for the government to influence the private decision of whether to work or become a nonworker. From a technical perspective, these employment effects resemble results derived in the literature on optimal taxation under involuntary unemployment ${ }^{9}$. At the same time, there is a fundamental difference; whereas the existence of involuntary unemployment implies that the income tax is used to affect employment via the labor demand, the employment effects discussed here are due to the desire to affect the individuals' decisions to participate in the labor market, which is part of the labor supply decision. Note that we can interpret $\Delta^{i}$ as the welfare effect following if one additional individual of ability-type $i$ chooses to become a

\footnotetext{
${ }^{9}$ See e.g. Aronsson and Sjögren (2003).
} 
nonworker, i.e.

$$
\begin{aligned}
\Delta^{i}= & \frac{\partial L}{\partial n^{i}}=\left\{-\rho\left[\bar{l}-l^{1}\right]-(\delta+\lambda) \rho\left[\bar{l}-l^{2}\right]+\lambda \rho\left[\bar{l}-\phi l^{1}\right]\right\} \frac{\partial \bar{l}}{\partial n^{i}} \\
& -\gamma\left[T\left(w^{i} l^{i}\right)+c^{0}\right]
\end{aligned}
$$

where our definition of $\bar{l}$ means that $\partial \bar{l} / \partial n^{1}>0$ and $\partial \bar{l} / \partial n^{2}<0$. The second row of equation (12) is the fiscal part of this welfare effect; it measures the decrease in the tax revenues net of transfer payment if one additional individual of ability-type $i$ chooses to become a nonworker times the marginal cost of public funds in utility terms. Therefore, to gain tax revenues, there is a fiscal incentive to reduce the number of nonworkers. The terms in the first row appear because the average hours of work among the employed depends on the number of nonworkers of each ability-type. To interpret these terms, we assume that $l^{2}>l^{1}$, as we did above. Consider first the effect of an increase in $n^{1}$, which leads to an increase in $\bar{l}$, ceteris paribus. This implies (i) a welfare loss facing the low-ability type because a higher $\bar{l}$ increases $\rho\left[\bar{l}-l^{1}\right]^{2}$, (ii) a welfare gain facing the high-ability type because a higher $\bar{l}$ reduces $\rho\left[\bar{l}-l^{2}\right]^{2}$, and (iii) a welfare gain because mimicking becomes less attractive, i.e. the mimicker must put in extra effort to mimick the lowability type. An increase in $n^{2}$ has the opposite effects in terms of the first row of equation (12), since an increase in $n^{2}$ reduces $\bar{l}$.

To provide further interpretations, let us add three assumptions, all of which appear to be intuitively reasonable; (i) $\Delta^{i}<0$, (ii) $\partial n^{j} / \partial c^{i}<0$ and (iii) $\partial n^{j} / \partial l^{i}>0$ for $i=1,2$, and $j=1,2$. The first assumption means that an increase in the number of nonworkers of ability-type $i$ decreases the welfare; for instance, that the fiscal part of this welfare effect is sufficiently strong. This may be more realistic in Western European countries than in many other countries due to the relatively high taxes and generous transfer programs in Western Europe. Each of the second and third assumptions 
contains two parts. First, if we were to increase $c^{i}\left(l^{i}\right)$, ceteris paribus, then the utility of being employed increases (decreases) relative to the utility of being a nonworker, suggesting that $\partial n^{i} / \partial c^{i}<0\left(\partial n^{i} / \partial l^{i}>0\right)$. Second, if $c^{i}$ $\left(l^{i}\right)$ increases, ceteris paribus, so the number of nonworkers of ability-type $i$ decreases (increases) by our earlier assumption, it will also follow that the perceived cost of being a nonworker for ability-type $j$ increases (decreases). This argument suggests that $\partial n^{j} / \partial c^{i}<0\left(\partial n^{j} / \partial l^{i}>0\right)$ for $j \neq i$. The latter is a consequence of social interaction, i.e. that the cost of being a nonworker facing each individual depends on the share of nonworkers in the economy as a whole. The comparative statics properties of the functions $n^{1}(\cdot)$ and $n^{2}(\cdot)$, given by equations (5) and (6), respectively, are formally addressed in the Appendix.

Therefore, with the additional assumptions made above, it follows that social interaction in terms of participation tends to strengthen the employment effects in each tax formula. Consider first the employment effect associated with the hours of work supplied by the low-ability type. A lower $l^{1}$ contributes to reduce $n^{1}$, which is an argument for reducing $l^{1}$ via a higher marginal income tax rate for the low-ability type. This argument is further strengthened if a lower $l^{1}$ also contributes to reduce $n^{2}$. Therefore, social interaction in terms of participation constitutes an additional motive for reducing the hours of work among the employed (here exemplified by the low-ability type) in order to make participation more attractive relative to nonparticipation. The idea of replacing work hours per employee by additional employees resembles work sharing, although the argument is, in this case, based on mechanisms referring to the supply (and not the demand) side of the labor market.

However, due to budget-balance arguments, there is also an indirect cost in terms of lost employment of a higher marginal income tax rate. To see 
this, note that a higher marginal income tax rate for the low-ability type, which reduces $l^{1}$, also tends to reduce $c^{1}$, since less resources will be available for private consumption. By the assumptions made earlier, this effect contributes to increase $n^{1}$ and $n^{2}$, where the latter is due primarily to social interaction. The more the consumption decreases in response to a given decrease in the hours of work, the weaker the employment-related argument for increasing the marginal income tax rates. It is not clear on theoretical grounds whether or not the direct employment effects following a change in the hours of work dominate the indirect employment effects, which are due to the associated changes in private consumption.

Turning to the marginal income tax rate of the high-ability type, the tax formula takes (almost) the same general form as, and is interpretable in a way similar to, the corresponding formula for the low-ability type. Except for the traditional self-selection term in the tax formula for the low-ability type, one apparent difference between the two formulas is that $-\alpha^{2} \lambda \rho\left[\bar{l}-\phi l^{1}\right]<0$ is a separate argument in the expression for the marginal income tax rate facing the high-ability type, while the corresponding expression for the low-ability type is hidden in $\widehat{M R S S}_{z, c}^{2}$. The result that the self-selection constraint directly affects the marginal income tax rate facing the high-ability type (and not just the marginal income tax rate of the low-ability type) differs from earlier literature on optimal income taxation. This is a consequence of social interaction in terms of work hours; $l^{2}$ affects $\bar{l}$ and, therefore, the selfselection constraint. To be more specific, this effect contributes to reduce the marginal income tax rate of the high-ability type. The intuition is that a lower marginal income tax rate increases $l^{2}$ and, as a consequence, $\bar{l}$. The latter makes mimicking less attractive, as it implies that the mimicker must put in more effort to reach the same level of consumption as the low-ability type. 


\section{Summary and Discussion}

This paper is a first attempt to incorporate social norms into the theory of optimal general income taxation in a two-type setting. We concentrate the analysis on social norms associated with the labor market and distinguish between two types of norms; (i) normal behavior with regards to work hours and (ii) the pressure to earn one's income from work. Social interaction affects norm formation in the sense that there is a perceived cost associated with deviating from the normal behavior with regards to work hours, where normal behavior is defined in terms of the average hours of work among the employed. Similarly, there is a perceived cost of being out of employment to each individual, which depends on the share of nonworkers (living on publicly provided benefits).

Since each individual is assumed to treat the average hours of work as exogenous during optimization, the social norm with regards to work hours gives rise to a corrective motive for taxation. As such, it may either contribute to increase or decrease the marginal income tax rates in comparison with the outcome under perfect competition. Under reasonable assumptions, this norm provides an incentive for the government to increase the hours of work supplied by the high-ability type relative to the hours of work supplied by the low-ability type. Furthermore, the possibility for the individual to choose to become a nonworker gives rise to so called 'employment effects' in the expressions for the marginal income tax rates, since the government can influence this choice via income taxation. Each of these employment effects are, in turn, likely to be magnified by social interaction, since an increase in the number of nonworking low-ability types reduces the cost of being out of employment for the high-ability type and vice versa.

Clearly, there an several ways of introducing social norms, and our study merely exemplifies how, and why, such norms may be relevant in the context 
of income taxation. Our message is that social norms may, in general, affect the income tax structure, both because the government wants to influence the hours of work decision made by those in employment, and because it wants to influence the incentives underlying the participation decision (or, more generally, the incentives to search for employment). It would be interesting to extend the analysis by allowing individuals of the same ability-type to differ with respect to the cost of deviating from normal behavior in terms of work hours, in which case this norm may be ability-type specific, as well as to incorporate social insurance more thoroughly. The latter may necessitate using an intertemporal model. We leave these and other extensions for future research.

\section{Appendix}

Let $\Delta^{i}=\partial L / \partial n^{i}$ be the derivative of the Lagrangean with respect to the number of nonworkers of ability-type $i$. The first order conditions can then be written as

$$
\begin{gathered}
0=\frac{\partial u^{1}}{\partial c^{1}}-\lambda \frac{\partial \hat{u}^{2}}{\partial c^{1}}-\gamma \check{N}^{1}+\sum_{i} \Delta^{i} \frac{\partial n^{i}}{\partial c^{1}} \\
0=-\frac{\partial u^{1}}{\partial z^{1}}+\rho\left[\bar{l}-l^{1}\right]\left[1-\frac{\partial \bar{l}}{\partial l^{1}}\right]-\delta \rho\left[\bar{l}-l^{2}\right] \frac{\partial \bar{l}}{\partial l^{1}}+\lambda\left\{-\rho\left[\bar{l}-l^{2}\right] \frac{\partial \bar{l}}{l^{1}}\right. \\
\left.+\frac{\partial \hat{u}^{2}}{\partial \hat{z}^{2}} \phi-\rho\left[\bar{l}-\phi l^{1}\right]\left[\phi-\frac{\partial \bar{l}}{\partial l^{1}}\right]\right\}+\gamma \check{N}^{1} w^{1}+\sum_{i} \Delta^{i} \frac{\partial n^{i}}{\partial l^{1}} \\
0=(\delta+\lambda) \frac{\partial u^{2}}{\partial c^{2}}-\gamma \check{N}^{2}+\sum_{i} \Delta^{i} \frac{\partial n^{i}}{\partial c^{2}} \\
=-\rho\left[\bar{l}-l^{1}\right] \frac{\partial \bar{l}}{\partial l^{2}}+(\delta+\lambda)\left\{-\frac{\partial u^{2}}{\partial z^{2}}+\rho\left[\bar{l}-l^{2}\right]\left[1-\frac{\partial \bar{l}}{\partial l^{2}}\right]\right\} \\
+\lambda \rho\left[\bar{l}-\phi l^{1}\right] \frac{\partial \bar{l}}{\partial l^{2}}+\gamma \check{N}^{2} w^{2}+\sum_{i} \Delta^{i} \frac{\partial n^{i}}{\partial l^{2}}
\end{gathered}
$$




$$
0=\zeta \frac{\partial u^{0}}{\partial c^{0}}-\gamma \check{N}^{0}+\sum_{i} \Delta^{i} \frac{\partial n^{i}}{\partial c^{0}}
$$

in which we have used the short notations $u^{i}=u\left(c^{i}, z^{i}\right)$ for $i=1,2, u^{0}=$ $\tilde{u}\left(c^{0}, H\right), \hat{u}^{2}=u\left(c^{1}, H-\phi l^{1}\right)$ and $\hat{z}^{2}=H-\phi l^{1}$.

\section{Proof of Proposition 1}

Consider first the marginal income tax rate facing the low-ability type. By using equations (A1) and (A2), we can derive

$$
\begin{aligned}
& \frac{\partial u^{1} / \partial z^{1}-\rho\left[\bar{l}-l^{1}\right]\left[1-\partial \bar{l} / \partial l^{1}\right]}{\partial u^{1} / \partial c^{1}}\left[\lambda \frac{\partial \hat{u}^{2}}{\partial c^{1}}+\gamma \check{N}^{1}-\sum_{i} \Delta^{i} \frac{\partial n^{i}}{\partial c^{1}}\right] \\
= & -\delta \rho\left[\bar{l}-l^{2}\right] \frac{\partial \bar{l}}{\partial l^{1}}+\lambda\left\{-\rho\left[\bar{l}-l^{2}\right] \frac{\partial \bar{l}}{l^{1}}+\frac{\partial \hat{u}^{2}}{\partial \hat{z}^{2}} \phi-\rho\left[\bar{l}-\phi l^{1}\right]\left[\phi-\frac{\partial \bar{l}}{\partial l^{1}}\right]\right\} \\
& +\gamma \check{N}^{1} w^{1}+\sum_{i} \Delta^{i} \frac{\partial n^{i}}{\partial l^{1}}
\end{aligned}
$$

Then, combining equations (3) and (A6), while assuming that $\lambda=0, n^{1}=0$ and $n^{2}=0$, we can derive the formula for $T^{\prime}\left(w^{1} l^{1}\right)$. The formula for $T^{\prime}\left(w^{2} l^{2}\right)$ can be derived in a similar way. Except for the additional restrictions imposed on $\lambda, n^{1}$ and $n^{2}$ above, the proof of Proposition 2 is analogous.

\section{Comparative Statics}

Define

$$
\begin{gathered}
\Lambda_{11}=-\rho\left[\bar{l}-l^{1}\right] \frac{\partial \bar{l}}{\partial n^{1}}+\frac{\partial \psi_{n}^{1}}{\partial \check{N}} \frac{1}{M}+\frac{\partial \psi_{n}^{1}}{\partial n^{1}} \\
\Lambda_{12}=-\rho\left[\bar{l}-l^{1}\right] \frac{\partial \bar{l}}{\partial n^{2}}+\frac{\partial \psi_{n}^{1}}{\partial \check{N}} \frac{1}{M} \\
\Lambda_{21}=-\rho\left[\bar{l}-l^{1}\right] \frac{\partial \bar{l}}{\partial n^{1}}+\frac{\partial \psi_{n}^{2}}{\partial \check{N}} \frac{1}{M} \\
\Lambda_{22}=-\rho\left[\bar{l}-l^{1}\right] \frac{\partial \bar{l}}{\partial n^{2}}+\frac{\partial \psi_{n}^{2}}{\partial \check{N}} \frac{1}{M}+\frac{\partial \psi_{n}^{2}}{\partial n^{2}}
\end{gathered}
$$


Differentiating equations (4), we have

$$
\begin{aligned}
\Lambda_{11} d n^{1}+\Lambda_{12} d n^{2}= & -\frac{\partial u^{1}}{\partial c^{1}} d c^{1}+\left(\frac{\partial u^{1}}{\partial z^{1}}-\rho\left[\bar{l}-l^{1}\right]\right. \\
& \left.+\rho\left[\bar{l}-l^{1}\right] \frac{\partial \bar{l}}{\partial l^{1}}\right) d l^{1}+\rho\left[\bar{l}-l^{1}\right] \frac{\partial \bar{l}}{\partial l^{2}} d l^{2}+\frac{\partial u^{0}}{\partial c^{0}} d c^{0} \\
\Lambda_{21} d n^{1}+\Lambda_{22} d n^{2}= & -\frac{\partial u^{2}}{\partial c^{2}} d c^{2}+\left(\frac{\partial u^{2}}{\partial z^{2}}-\rho\left[\bar{l}-l^{2}\right]\right. \\
& \left.+\rho\left[\bar{l}-l^{2}\right] \frac{\partial \bar{l}}{\partial l^{2}}\right) d l^{2}+\rho\left[\bar{l}-l^{2}\right] \frac{\partial \bar{l}}{\partial l^{1}} d l^{1}+\frac{\partial u^{0}}{\partial c^{0}} d c^{0}
\end{aligned}
$$

In addition, define

$$
|\Omega|=\Lambda_{11} \Lambda_{22}-\Lambda_{12} \Lambda_{21}
$$

The comparative statics of $n^{1}$ can then be written as

$$
\begin{gathered}
\frac{\partial n^{1}}{\partial c^{1}}=-\frac{1}{|\Omega|} \frac{\partial u^{1}}{\partial c^{1}} \Lambda_{22} \\
\frac{\partial n^{1}}{\partial l^{1}}=\frac{1}{|\Omega|}\left\{\left[\frac{\partial u^{1}}{\partial z^{1}}-\rho\left[\bar{l}-l^{1}\right]+\rho\left[\bar{l}-l^{1}\right] \frac{\partial \bar{l}}{\partial l^{1}}\right] \Lambda_{22}-\rho\left[\bar{l}-l^{2}\right] \frac{\partial \bar{l}}{\partial l^{1}} \Lambda_{12}\right\} \\
\frac{\partial n^{1}}{\partial c^{2}}=\frac{1}{|\Omega|} \frac{\partial u^{2}}{\partial c^{2}} \Lambda_{12} \\
\frac{\partial n^{1}}{\partial l^{2}}=\left\{\rho\left[\bar{l}-l^{1}\right] \frac{\partial \bar{l}}{\partial l^{2}} \Lambda_{22}-\left[\frac{\partial u^{2}}{\partial z^{21}}-\rho\left[\bar{l}-l^{2}\right]+\rho\left[\bar{l}-l^{2}\right] \frac{\partial \bar{l}}{\partial l^{2}}\right] \Lambda_{12}\right\} \\
\frac{\partial n^{1}}{\partial c^{0}}=\frac{1}{|\Omega|} \frac{\partial u^{0}}{\partial c^{0}}\left[\Lambda_{22}-\Lambda_{12}\right]
\end{gathered}
$$

The comparative statics of $n^{2}$ are analogous. 
To motivate the additional assumptions about the properties of $n^{1}(\cdot)$ and $n^{2}(\cdot)$ made in subsection 3.2, consider equations (A7)-(A10). Since we would like to concentrate on the decision of whether or not to participate, and not the hours of work among the employed, suppose that the indirect effects of $n^{1}$ and $n^{2}$ via $\bar{l}$ are not strong enough to dominate the other terms. In addition, to ensure that we are actually ranking the individuals from the lowest to the higherst cost of being out of employment, we assume that $\left(\partial \psi_{n}^{i} / \partial \check{N}\right)(1 / M)+\partial \psi_{n}^{i} / \partial n^{i}>0$ for $i=1,2$. These two assumptions mean $\Lambda_{11}>0, \Lambda_{12}<0, \Lambda_{21}<0$ and $\Lambda_{22}>0$. Then, if $|\Omega|>0$, which is reasonable by similar arguments, a possible (and arguably likely) outcome of equations (A14)-(A17) would be $\partial n^{1} / \partial c^{1}<0, \partial n^{1} / \partial l^{1}>0, \partial n^{1} / \partial c^{2}<0$ and $\partial n^{1} / \partial l^{2}>0$.

\section{References}

[1]Aronsson, T., Blomquist, S. and Sacklen, H. (1999) How to Identify Interdependent Behaviour in an Empirical Model of Labor Supply. Journal of Applied Econometrics 14, 607-626.

[2]Aronsson, T. and Sjögren, T. (2003) Income Taxation, Commodity Taxation and Provision of Public Goods under Labor Market Imperfections. Finanzarchiv 59, 347-370.

[3]Aronsson, T. and Sjögren, T. (2004) Is the Optimal Labor Income Tax Progressive in a Unionized Economy?. Scandinavian Journal of Economics 106, 661-675.

[4]Blomquist, S. (1993) Interdependent Behavior and the Effect of Taxes. Journal of Public Economics 51, 211-218.

[5]Bruvoll, A. and Nyborg, K. (2004) The Cold Shiver of not Giving 
Enough: On the Social Costs of Recycling Campaigns. Land Economics 80, 540-549.

[6]Fuest C. and Huber. B. (1997) Wage Bargaining, Labor-Tax Progression, and Welfare. Journal of Economics 66, 127-150.

[7]Jakke, K. and Sun, G-Z. (2005) External Habit Formation and Dependency in the Welfare State. European Journal of Political Economy 21, 83-98.

[8]Lindbeck, A. (1995) Welfare State Disincentives with Endogenous Habits and Norms. Scandinavian Journal of Economics 97, 477-494.

[9]Lindbeck, A., Nyberg, S. and Weibull, J. (1999) Social Norms and Economic Incentives in the Welfare State. Quarterly Journal of Economics 114, 1-35.

[10]Lindbeck, A., Nyberg, S. and Weibull, J. (2003) Social Norms and Welfare State Dynamics. Journal of the European Economic Association 1, 533-542.

[11]Stern, N., H. (1982), "Optimum taxation with errors in administration", Journal of Public Economics 17, 181-211.

[12]Stiglitz, J.E. (1982) Self-Selection and Pareto Efficient Taxation. Journal of Public Economics 17, 213-240.

[13]Wendner, R. (2005) Frames of reference, the Environment and Efficient Taxation. Economics of Governance 6, 13-31.

[14]Woittiez, I. and Kapteyn, A. (1998) Social Interaction and Habit Formation in a Model of Female Labor Supply. Journal of Public Economics 70, 185-205. 